\title{
"A brain to pick, an ear to listen and a push in the right direction" (John C. Crosby)
}

Catherine Farrant, Julia Tybura, Melanie Rafe (Khi), Nelly Ackon; Marie-Christin Schmidt, Amonlath Chantaboury

University of Greenwich, UK

\begin{abstract}
This paper provides the context and background to a 'Student Peer Mentoring' scheme that was co-created with students and piloted within the Business Faculty in University of Greenwich. We reflect on sharing this experience at the annual SHIFT ${ }^{1}$ conference on Teaching, Learning and Assessment and the lessons learned that will support the further development of this scheme. Key themes that arose were around the value of mentoring to support first year students and the benefit for mentors in terms of their own self confidence and development as evidenced by their contribution to SHIFT. Lessons learnt were the need to provide more guidance to mentees in preparation for mentoring and providing supervision support to mentors to allow them to reflect on issues that arise out of mentoring. Our complex approach to evaluation was challenged given the small numbers of numbers of mentors and mentees. We concluded that qualitative evidence gives enough support for the success of this scheme. It is planned to provide mentor training to all students on a voluntary basis leading to enhanced peer relationships and support.
\end{abstract}

Keywords: peer mentoring; student support; retention; active listening; development

\section{Introduction}

\section{Overview}

Four student mentors and two academics - both qualified coaches - from the Business Faculty of University of Greenwich shared, at SHIFT $2021^{1}$, an overview of the Human Resource and Organisational Behaviour department's 'Student Peer Mentoring' scheme. This scheme was initiated by the Year 1 programme lead to provide an additional layer of support, beyond that provided by academic and personal tutors. The lead academics were mindful of the purpose of mentoring, a mentor's journey alongside the mentee to guide the latter's own decision-making. Mentors were trained using the Arnold (2016) characteristics of mentoring and the 'Stop Think Ask Reflect Trust' (START) framework.

We recruited fifteen mentors only half-way through the autumn term, owing to logistic challenges caused by the pandemic. We recruited them on a voluntary basis; they qualified by being on a relevant undergraduate programme and having the motivation to be mentors.

\footnotetext{
${ }^{1} \mathrm{~A}$ teaching, learning and assessment conference organised annually by University of Greenwich.
} 


\section{Pedagogy and design}

We provided student mentors with a two-hour training workshop, predicated on research by Gray et al. (2016) which encourages 'active listening' and 'powerful questioning'. We see these as a firm basis for helping mentees "maximise their personal and professional potential' (ICF, 2017). We shared with them the Arnold (2016) mentoring framework (table 1) to help them to understand what mentoring is:

\begin{tabular}{|l|l|}
\hline Advises and suggests & Shares knowledge and experience \\
\hline May need to make judgements & Guides to a decision \\
\hline Leads by example & Gives examples and ideas \\
\hline Helps to develop & May work over a long period \\
\hline Is usually more experienced & Takes a broader view \\
\hline Stands close & \\
\hline Can feel responsible & \\
\hline
\end{tabular}

Table 1: The Arnold mentoring framework

and provided them with the START framework (Arnold, 2016) as an approach to mentoring. We also shared the GROW (Goals, Reality, Options, Will) model (Whitmore, 2017) as one means of helping mentees identify what they want to achieve.

Following the workshop, the mentors, having been allocated forty-five mentees between them, connected with half of these by end of term 1. At this point, Catherine Farrant, Lead Tutor, held a supervision session with mentors, in order to listen to their experiences so far, identify issues and offer support. Supervision helped them reflect on skills and approaches and threw up some interesting issues concerning transference, by which we mean that the mentor takes on some of the anxieties of the mentee (McCauley 2003) and demonstrates self-doubt. The supervision session helped them to understand the importance of setting clear boundaries in relation to what support a mentor can offer as distinct from counselling or personal tutor support (Arnold, 2016) and begin to develop self-confidence in their mentoring role (Couchman 2009).

Subsequent surveys and interviews gathered feedback from mentors and mentees. Early indicators were that the scheme was successful at developing mentor skill and confidence and that those mentees who engaged did benefit. Our original plan was complex - to analyse a range of hard data and measure impact on academic outcomes and self-efficacy (Zimmerman et al., 1992). Co-presenting at SHIFT has led to reflection on the viability of this ambition. 


\title{
Conference reflections
}

\section{Reflection}

Reflection is a key part of coaching and mentoring interventions and "plays a crucial role in progressing understanding in paradoxical situations" (Gray et al., 2016, p.106). As the theme of the conference was co-creation with students, we asked student mentors to reflect on their mentoring experience and present this at the conference. Their presentation reflections are summarised here:

Khi became worried that her mentees were not engaging with her and took this personally when it was not her fault and was simply due to conflicting demands and time constraints for both mentor and mentee. Her evident anxiety coupled with the feedback from other mentors; tell us we need to provide some guidance to mentees on how to plan for and make the most of their mentoring sessions. We also need to start the process earlier, before assignment pressure begins, to give time for relationships to form. Additionally, Khi's experience underlines the importance of supervision as a way to share ideas and reassure mentors about their role and contribution (Bachkirova et al., 2012).

Nelly reflected that a student peer mentor is perceived as more accessible and relatable than a personal tutor and can act as a bridge or supplement to personal tutoring. This means mentors need to be clear about how to manage boundaries, understanding when they need to refer to a specialist academic tutor or mental health support counsellor (Barnett, 2008). This was underlined by Marie-Christin, whose very challenging case - a late starter with no timetable and missed assignments - led her, proactively, to seek support and guidance from her mentoring supervisor.

And finally, Cert shared an eloquent video-clip on how developmental being a mentor was for her - enhancing her self-confidence and personal growth.

Presenting at SHIFT as well as attending a range of presentations was a new experience for our student mentors Nelly, Khi and Marie-Christin and caused them to have many conflicting feelings.

\author{
"I started feeling extremely nervous"; \\ "I was excited, curious and nervous to present"; \\ "Anxiety had me fidgeting behind the screen undetected"; \\ "I'm really looking forward to this!"
}

The students were hugely proud of themselves once the presentation finished and we and they evaluated their contribution as highly effective. It was energising to see how capable and engaged our students are and what an enormous contribution they can make to the institution and its community. They added huge value to the discussion, fielding questions and sharing insights.

"Everything worked out as planned, and we got good feedback about the scheme and the presentation"; 
"...by the time I was sharing my experience as a student mentor, I felt comfortable";

"the students presented very well, and we got some great questions and positive feedback'.

They learnt from this experience of presenting and also much more from the other talks they attended.

"It was an invaluable experience, where I developed personally very much, learned a lot about many important topics, and I got insights about the teaching perspective at the University. It showed me how much is being done to make universities a better place";

"I was glad that my contribution gave people some insight as I have also gained insights about different interesting topics";

“... one earlier speaker highlighted the support needed for older mature students returning to HE impressed me, as I related the points raised to my experiences";

"... it provided a deeper insight into HE on a macro level, and the presentation experience will strengthen my skills and confidence for a video interview".

Through this novel experience, students gained valuable knowledge, presentation and teamworking skills and thus improved their academic and employability skills. More importantly, they contributed to an important discussion about how we can harness the power of student relationships and peer support to engage the wider community, improving student outcomes and retention. We reflected that use of mentors were effective 'listening ears' providing opportunities for mentees to 'pick their brains' and giving them a 'push in the right direction' (Crosby nd).

To train mentors phenomenologically seems to us a powerful approach, enabling serendipitous insights into mentoring, while also considering the notion of choice (Watson, 2002; Burnes, 2017).

As coaches, we have reflected on the need for deeper and more structured supervision of mentors. We have identified the need to recruit and train mentors earlier, to allow the relationship time to develop before the pressures of academic achievement build up. We recognise the challenge of finding hard measures for outcomes; as this was a small sample, measuring both academic outcomes and self-efficacy quantitatively will not provide meaningful data. We continue to gather the data and hope over time to have a meaningful sample size. We will meanwhile, gather qualitative feedback to identify impact on both mentees and mentors at the end of term 2.

Lastly, it seems to us that giving all students mentoring skills will enhance their own selfefficacy and allow them to provide support and challenge to each other more effectively. We 


\section{Conference reflections}

plan to offer extended mentoring workshops that allow practice in triads, with follow-up supervision for all students as a voluntary choice, building a more informal community of practice (Wenger-Trayner and Wenger-Trayner, 2015) where all can reflect, share and learn in a different way.

\section{Reference list}

Arnold, J. (2016) Coaching Skills for Leaders in the Workplace. How to unlock potential and maximise performance. $2^{\text {nd }}$ edition. London: Robinson. ISBN: 978-1845285685

Bachkirova, T., Jackson P. and Clutterbuck D. (2011) Coaching and Mentoring Supervision: Theory and Practice: The complete guide to best practice. Maidenhead: OUP. ISBN: 9780335242986

Barnett, J. (2008) 'Mentoring, boundaries and multiple relationships: opportunities and challenges.' Mentoring and Tutoring, Partnership in Learning, 16(1), 3-16.

Burnes, B. (2017) Managing Change. London: Pearson. ISBN: 9781292156040

Couchman, J.A. (2009) 'An exploration of the Lived experience of one Cohort of Academic Peer Mentors at a small Australian University.' Journal of Peer Learning, (2)5, 87-110. Available at: https://core.ac.uk/download/pdf/36977047.pdf (Accessed: 18 May 2021).

Crosby, J.C. (nd) Available at:

https://www.open.edu/openlearn/ocw/mod/oucontent/view.php?id=74032\&section=2.1

(Accessed:18 May 2021)

Gray, D.E., Garvey B. and Lane D.A. (2016) A Critical Introduction to Coaching and Mentoring: Debates, Dialogues and Discourses. London: Sage. ISBN: 9781446272282

ICF (2017) 'ICF Core Competencies.' Available at: https://coachfederation.org/corecompetencies (Accessed: 18 May 2021).

Mcauley, M. (2003) 'Transference, countertransference and mentoring: The ghost in the process.' The British Journal of Guidance and Counselling, 31(1),11-23. Available at: https://www.researchgate.net/publication/233606774 Transference countertransference an d mentoring The ghost in the process (Accessed: 18 May 2021).

Watson, A. (2003) 'Strategists and Strategy-making: strategic exchange and the shaping of individual lives and organisational futures.' Journal of Management Studies, 40(5). https://doi.org/10.1111/1467-6486.00381

Wenger-Trayner, E. and Wenger-Trayner, B. (2015) 'Introduction to Communities of Practice.' Available at: https://wenger-trayner.com/introduction-to-communities-of-practice/ (Accessed: 17 February 2021).

Whitmore, J. (2017) Coaching for Performance: The principles and practice of coaching and leadership. $5^{\text {th }}$ edition. London: Nicholas Brealey Publishing. ISBN: 978-1473658127 
Zimmerman, B.J, and Martinez-Pons, M. (1992) 'Self-Motivation for Academic Attainment: The role of Self-Efficacy Beliefs and Personal Goal Setting.' American Educational Research Journal, 29(3), 663-676. Available at: https://www.jstor.org/stable/1163261 (Accessed: 18 May 2021). 